\title{
Obtaining Experimental Values of the Uniformity of Seed Distribution by Multivariate Regression Analysis
}

\author{
Evgeniy V. Demchuk, Grigoriy V. Redreev, Vladimir V. Myalo, Ol'ga V. Myalo, \\ and Sergey P. Prokopov
}

FSBEI HE Omsk SAU, 1 Fizkulturnaya St., Omsk, Russian Federation

ORCID:

Evgeniy V. Demchuk: http://orcid.org/0000-0001-5139-4909

\section{Abstract}

One of the key factors affecting agricultural productivity is the availability of technical means that include machine and tractor units of agricultural enterprises. The production volume of the plant growing industry depends on high yields that can be achieved by high-quality sowing, which implies the optimal seed placement and sowing depth. Thus, the modernization of existing seeding machines and the creation of new ones

Corresponding Author: Evgeniy V. Demchuk ev.demchuk@omgau.org

Published: 5 April 2021

Publishing services provided by Knowledge E

(c) Evgeniy V. Demchuk et al. This article is distributed under the terms of the Creative Commons Attribution License, which permits unrestricted use and redistribution provided that the original author and source are credited.

Selection and Peer-review under the responsibility of the DonAgro Conference Committee. that ensure the optimal seed placement is an urgent task. This study aimed to develop a coulter for uniform seed distribution along the furrow length. The object of the study was uniform sowing patterns for grain crops based on the optimal parameters of the proposed working unit of the seeding machine obtained by multivariate regression analysis. A symmetric orthogonal compositional plan of the second order was chosen as a model. The criterion for optimization of the geometric parameters of the developed coulter was the uniformity of seed distribution along the furrow length. The following parameters of the proposed coulter were changed: the cut length of the outer side of the rectilinear profile of the lower edge of the rack varied within $20-80 \mathrm{~mm}(\mathrm{~L})$, and the approach angle in the horizontal plane $(\alpha)$ and the roll angle in the vertical plane $(\beta)$ varied within 3-28 deg. The study yielded the regression equation for constructing the response surfaces. The analysis of the response surfaces showed that the optimal parameters for uniform seed distribution along the furrow length can be achieved at the approach angle $\alpha=250$, the roll angle $\beta=150$, and the cut length of the lower edge of the rack $\mathrm{L}=50 \mathrm{~mm}$.

Keywords: Coulter, sowing, grain, quality, distribution uniformity, multivariate experiment

\section{G OPEN ACCESS}

\section{Introduction}

Welfare, raising living standards and employment of citizens, sustainable development of rural areas, preservation of territorial integrity and ensuring the national security of the 
Russian Federation are key priorities of the State Program for Agribusiness Development and Regulation of Agricultural Products, Raw Materials and Food Markets in 2013-2020.

The program aims to ensure food independence of Russia based on the Doctrine of Food Security of the Russian Federation; to increase the competitiveness of Russian agricultural products in the domestic and foreign markets; to improve the financial stability of agricultural enterprises; to ensure sustainable development of rural areas; to increase the efficient use of agricultural land and other resources, as well as greening of production [1].

According to the Strategy for machine and technological modernization of agribusiness in Russia, the machine and technological complex of agribusiness, as the basis for agricultural production, is a significant socially oriented production system that regulates the volume, quality and economic characteristics of the final agricultural product and includes agricultural technologies for production of these products performed by machine units, and technical means and infrastructure that ensure the system efficiency [2]. At the same time, according to the Concept of scientific development of the Russian agro-industrial complex until 2025, innovative technologies for manufacturing high quality products, resource conservation, environmental safety, competitiveness in the world market, development of fundamentally new high-performance and resourcesaving machines and equipment, are being developed in order to effectively implement the priority national project Agribusiness development [3]. Thus, one of the key factors that determine the growth rate of agricultural production is the availability of technical means that include machine and tractor units of agricultural enterprises.

An increase in production volumes and in the competitiveness of agribusiness is inextricably linked with agricultural science, which ensures the development of innovative approaches and introduction of effective technologies that are most appropriate for the climatic conditions and regional characteristics of agricultural production $[4,5]$.

The production volume of the plant growing industry depends on high yields that can be achieved by high-quality sowing of agricultural crops [6,7]. High-quality sowing implies the optimal seed placement and sowing depth [8]

To date, drill sowing is the most widespread method of sowing, however, this method has an apparent drawbacks such as thickened rows and the area of plant nutrition in the form of a rectangle with aspect ratio of 1:10, while the optimal placement of plants is triangulation $[9,10]$.

Based on the above, we can conclude that the modernization of existing seeding machines and the creation of new ones to ensure the optimal placement of seeds is an urgent task 
The purpose of the study is to develop a coulter that ensures uniform seed distribution along the furrow length

\section{Methods and Equipment}

To describe the patterns of seed distribution along the furrow length, a planned experiment is carried out to reveal the impact of factors on the studied indicator. The criterion for optimization of the geometric parameters of the proposed coulter is the uniformity of seed distribution along the furrow length. Table 01 presents a symmetric orthogonal compositional plan of the second order that was chosen as a model. Table 02 shows the distribution of factors by levels of variation.

TABLE 1: Experiment planning matrix

\begin{tabular}{|l|c|c|c|c|c|c|c|c|c|c|c|}
$\begin{array}{l}\text { Experiment } \\
\text { no. }\end{array}$ & X0 & X1 & X2 & X3 & X1X2 & X1X3 & X2X3 & X1X1 & X2X2 & X3X3 & $\begin{array}{c}\text { Y average } \\
\text { (by length) }\end{array}$ \\
\hline 1 & 1 & 1 & 1 & 1 & 1 & 1 & 1 & 1 & 1 & 1 & 0.7219 \\
\hline 2 & 1 & -1 & 1 & 1 & -1 & -1 & 1 & 1 & 1 & 1 & 0.7041 \\
\hline 3 & 1 & 1 & -1 & 1 & -1 & 1 & -1 & 1 & 1 & 1 & 0.6838 \\
\hline 4 & 1 & -1 & -1 & 1 & 1 & -1 & -1 & 1 & 1 & 1 & 0.6844 \\
\hline 5 & 1 & 1 & 1 & -1 & 1 & -1 & -1 & 1 & 1 & 1 & 0.7494 \\
\hline 6 & 1 & -1 & 1 & -1 & -1 & 1 & -1 & 1 & 1 & 1 & 0.7362 \\
\hline 7 & 1 & 1 & -1 & -1 & -1 & -1 & 1 & 1 & 1 & 1 & 0.691 \\
\hline 8 & 1 & -1 & -1 & -1 & 1 & 1 & 1 & 1 & 1 & 1 & 0.6942 \\
\hline 9 & 1 & 1.215 & 0 & 0 & 0 & 0 & 0 & 1.476225 & 0 & 0 & 0.8295 \\
\hline 10 & 1 & -1.215 & 0 & 0 & 0 & 0 & 0 & 1.476225 & 0 & 0 & 0.804125 \\
\hline 11 & 1 & 0 & 1.215 & 0 & 0 & 0 & 0 & 0 & 1.476225 & 0 & 0.68435 \\
\hline 12 & 1 & 0 & -1.215 & 0 & 0 & 0 & 0 & 0 & 1.476225 & 0 & 0.7347 \\
\hline 13 & 1 & 0 & 0 & 1.215 & 0 & 0 & 0 & 0 & 0 & 1.476225 & 0.685875 \\
\hline 14 & 1 & 0 & 0 & -1.215 & 0 & 0 & 0 & 0 & 0 & 1.476225 & 0.746675 \\
\hline 15 & 1 & 0 & 0 & 0 & 0 & 0 & 0 & 0 & 0 & 0 & 0.877625 \\
\hline
\end{tabular}

TABLE 2: Levels of variation of factors

Factor
Coded designation
Main level $\left(X_{i 0}\right)$
Variation interval $\left(\Delta X_{i}\right)$
Upper level $\left(X_{i}=1\right)$
Lower level $\left(X_{i}=-1\right)$
Star point $+\alpha\left(X_{i}=2\right)$
Star point $-\alpha\left(X_{i}=2\right)$

\begin{tabular}{|c|c|}
$\begin{array}{c}\text { Approach angle } \\
\alpha, \text { deg }\end{array}$ & Roll angle $\beta$, deg \\
\hline$X_{1}$ & $X_{2}$ \\
\hline 15 & 15 \\
\hline 10 & 10 \\
\hline 25 & 25 \\
\hline 5 & 5 \\
\hline 2.85 & 2.85 \\
\hline 27.15 & 27.15 \\
\hline
\end{tabular}

Cut length $\mathrm{L}, \mathrm{mm}$
\[ \begin{array}{c}X_{3} \\ 50 \\ 25 \\ 75 \\ 25 \\ 80.375 \\ 19.625\end{array} \]


The planned experiment results in the following model: [11, 12]:

$$
y=b_{0}+\sum_{1 \leq i \leq k} b_{i} x_{i}+\sum_{1 \leq i \leq j \leq k} b_{i j} x_{i} x_{j}+\sum_{1 \leq i \leq k} b_{i i} x_{i}^{2}
$$

To eliminate systematic errors caused by external conditions, experiments were randomized according to the table of random numbers. The number of replicates of each experiment during the planned experiment is calculated using the formula for calculating probabilities 0.95 [13].

$$
n=\frac{S_{y}^{2}}{0.05 \tau^{2}}
$$

where Sy is standard deviation;

$\tau$ is $5 \%$ of $\bar{y}$;

$\bar{y}$ is arithmetic mean.

According to the calculation results, the number of replicates of each experiment was taken equal to four.

The variance is calculated for each experiment:

$$
S_{y_{u}}^{2}=\frac{\left(y_{u_{g}}-\bar{y}_{u}\right)^{2}}{(n-1)}
$$

where yug is the result of the g-th replication;

$\bar{y}_{u}$ is the arithmetic mean of $u$-th repetition.

To determine the possibility of conducting regression analysis, the homogeneity of the variances of parallel experiments is calculated using the Cochran's test:

$$
G^{c a l c}=\frac{S_{y_{u}}^{2} \max }{\sum_{u=1}^{N} S_{y_{u}}^{2}}
$$

where $S_{y_{u}}^{2}$ max is the largest variance in the series.

The calculated value of the GCALC criterion is compared with the value of the Cochran test, depending on the level of significance, the number of degrees of freedom $f=N-1$ and the number of experiments [14].

A series of dispersions is considered homogeneous if $G_{P}<G_{t a b}$.

The reproducibility variance is calculated using the formula:

$$
S_{y}^{2}=\frac{\sum_{u=1}^{N} S_{y_{u}}^{2}}{N}
$$

where $\mathrm{N}$ is the number of independent experiments.

The experiment using an orthogonal symmetric compositional plan involves, first of all, obtaining a process model:

$$
y=b_{0}^{\prime}+\sum_{i=1}^{k} b_{i} x_{i}+\sum_{i<j}^{k} b_{i j} x_{i} x_{j}+\sum_{i=1}^{k} b_{i i} x_{i}^{2},
$$


The model coefficients are estimated independently of each other using the formulas:

$$
\begin{gathered}
b_{0}^{\prime}=\frac{\sum_{u=1}^{N} n_{u} \bar{y}_{u}}{\sum_{u=1}^{N} n_{u}} \quad b_{i}=\frac{\sum_{u=1}^{N} n_{u} x_{i u} \bar{y}_{u}}{\sum_{u=1}^{N} n_{u} x_{i u}^{2}}, \\
b_{i j}=\frac{\sum_{u=1}^{N} n_{u}\left(x_{i} x_{j}\right)_{u} \bar{y}_{u}}{\sum_{u=1}^{N} n_{u}\left(x_{i} x_{j}\right)_{u}^{2}} \quad b_{i i}=\frac{\sum_{u=1}^{N} n_{u} x_{i u}^{\prime} \bar{y}_{u}{ }^{2}}{\sum_{u=1}^{N} n_{u} x_{i u}^{\prime}{ }^{2}}
\end{gathered}
$$

where $u$ is the ordinal number of the experiment.

The variance of the coefficient estimates is calculated by the formulas:

$$
\begin{gathered}
S_{b_{0}^{\prime}}^{2}=\frac{S_{y}^{2}}{\sum_{u=1}^{N} n_{u}}, \quad S_{b_{i}}^{2}=\frac{S_{y}^{2}}{\sum_{u=1}^{N} n_{u} x_{i u}^{2}}, \\
S_{b_{i j}}^{2}=\frac{S_{y}^{2}}{\sum_{u=1}^{N} n_{u}\left(x_{i} x_{j}\right)_{u}^{2}}, \quad S_{b_{i i}}^{2}=\frac{S_{y}^{2}}{\sum_{u=1}^{N} n_{u} x_{i u}^{\prime 2}} .
\end{gathered}
$$

After calculating the regression equation coefficients, they are checked for statistical significance. The confidence interval is calculated using the formula:

$$
\Delta b_{i}=t_{\alpha ; f_{1}} S_{b_{i}}
$$

where $t$ is the Student's criterion, which is chosen depending on the level of significance and the number of degrees of freedom.

$S_{b_{i}}$ is the root-mean-square error in determining the regression coefficients.

Then the coefficient significance is determined. The coefficient is considered statistically significant when its absolute value is greater than or equal to the confidence interval:

$$
\left|b_{i}\right| \geq \Delta b_{i}
$$

In orthogonal planning, statistically insignificant coefficients can be excluded from the model, while other coefficients need not be recalculated. After calculating the coefficients and checking their statistical significance, go from model (6) to model (1), calculating the value of bo:

$$
\begin{gathered}
b_{0}=b_{0}^{\prime}-\lambda_{2} \sum_{i=1}^{k} b_{i i}, \\
\lambda_{2}=N^{-1} \sum_{u=1}^{N} x_{i u}^{2},
\end{gathered}
$$

Since the coefficients $b^{\prime} 0$ and bii are estimated independently of each other, the variance $S_{b_{0}}^{2}$ is determined by the law of error accumulation:

$$
S_{b_{0}}^{2}=S_{b_{0}^{\prime}}^{2}+\lambda_{2}^{2} \sum_{i=1}^{k} S_{b_{i i}}^{2},
$$


The obtained model is checked for adequacy using the Fisher's test by the formulas:

$$
F_{f_{2} ; f_{1}}^{\text {calc }}=\frac{S_{\text {inad }}^{2}}{S_{y}^{2}},
$$

where $\mathrm{f} 2$ is the denominator;

$\mathrm{f} 1$ is the numerator;

$S_{\text {inad }}^{2}$ is the variance of inadequacy.

$$
f_{2}=N-k^{\prime},
$$

where $k^{\prime}$ is the number of equation coefficients left (including b0);

$\mathrm{N}$ is the number of planned experiments.

$$
f_{1}=N(n-1),
$$

where $\mathrm{n}$ is the number of replications of each experiment.

$$
\begin{gathered}
S_{\text {inad }}^{2}=\frac{S S_{\text {inad }}}{f_{2}}, \\
S S_{\text {inad }}=n \sum_{u=1}^{N}\left(y_{u_{\text {calc }}}-\bar{y}_{u_{\text {exp }}}\right)^{2},
\end{gathered}
$$

where yu calc $u$ yu exp are the response values in the u-th experiment calculated by the regression equation and determined experimentally.

The hypothesis about the equation adequacy can be accepted when the value of the Fisher's test obtained as a result of calculations does not exceed the tab value for the selected level of significance, that is, when Ftab $\geq$ Fcalc

\section{Results}

Based on the results of the study, a double disk coulter was developed (Figure 1) [15]. The process of uniform seed distribution along the furrow length is affected by many factors: design parameters of the coulter, technological parameters of the sowing unit, agrotechnical requirements. Since the available coulters are installed on the seeding machine with a standard row spacing of $150 \mathrm{~mm}$, it is necessary to ensure uniform seed distribution along the furrow length in order to prevent seed thickening in the row.

In the experimental studies, the following parameters of the proposed coulter were changed: the cut length of the outer side of the rectilinear profile of the lower edge of the rack varied within $20-80 \mathrm{~mm}(L)$, the approach angle in the horizontal plane $(\alpha)$ and the roll angle in the vertical plane $(\beta)$ varied within 3-28 deg. 


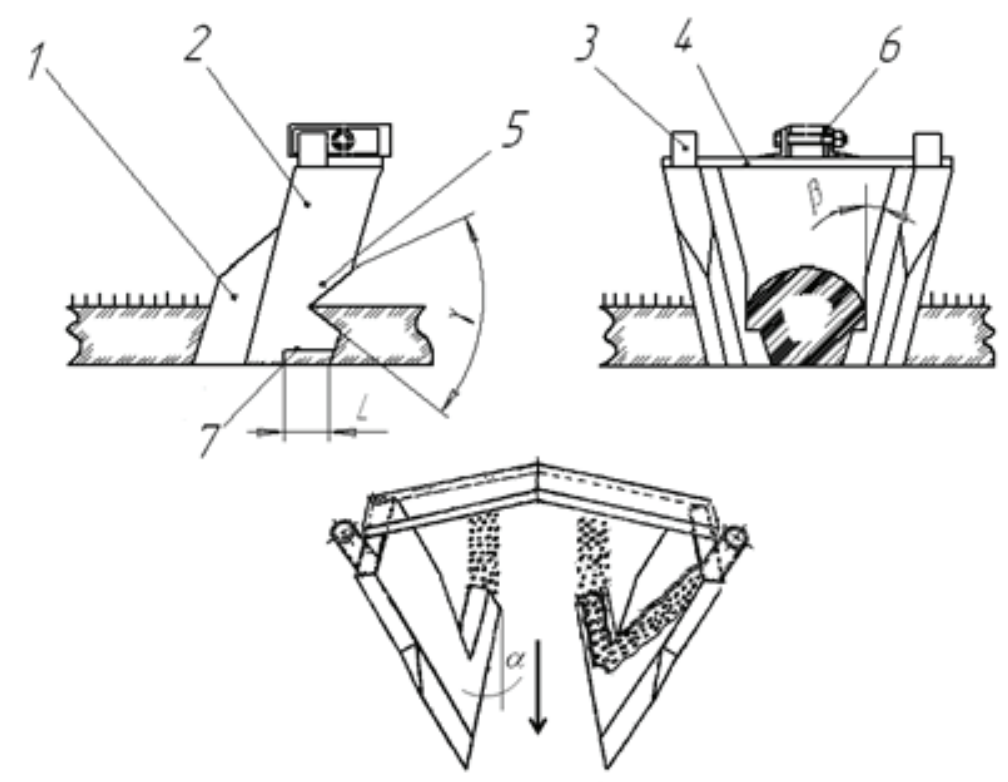

Figure 1: Double disk coulter: 1 - plate with a pointed tip, 2 - hollow rack, 3 - seed guide, 4 - holder, 5 cut with a convergence angle $\gamma, 6$ - mounting rack, 7 - cut made outside the straight profile of the lower edge, $\alpha$ - approach angle, $\beta$ - roll angle, $L$ - cut length

In the study, a second-order model was obtained. Check for the homogeneity of a number of variances using the Cochran's test showed that a number of variances can be considered homogeneous $G^{\text {calc }}=0.2141<G^{\text {tab }}=0.2758$.

As a result, the regression equation was obtained to describe the process of changing the uniformity of the seed distribution along the furrow length in coded values. The confidence interval of the regression coefficients calculated by the formula (9) $\Delta \mathrm{bi}=$ 0.000473 makes it possible to recognize the coefficients as statistically significant, the absolute value of which is equal to the confidence interval or greater, so the equation has the following form:

$\mathrm{Y}=0.824731+0.005298 \cdot \mathrm{x} 1+0.008886 \cdot \mathrm{x} 2-0.01374 \cdot \mathrm{x} 3+0.00435 \cdot \mathrm{x} 12-0.00533$ $\mathrm{x} 13-0.00533 \mathrm{x} 23++0.006014 \cdot \mathrm{x} 11-0.0666 \cdot \mathrm{x} 22-0.06204 \cdot \mathrm{x} 33$

The preliminary analysis of the regression equation shows that:

1. The most significant factor is the cut length of the lower edge of the rack $(x 3)$. However, its increase leads to a decrease in the quality of seed distribution, as indicated by the minus sign in front of $(x 3)$. The least significant factor is the approach angle $(x 1)$, but its increase leads to an increase in the uniformity of seed distribution along the furrow length, as evidenced by the plus sign in front of $(\mathrm{x} 1)$. A similar pattern is observed for $(x 2)$ that indicates the effect of the roll angle.

2. Since the quadratic coefficients $(x 11, x 22, x 33)$ are present in the equation, the model is nonlinear and the response surfaces should be described by curves of the 
second order. The minus sign in front of $x 22$ and $x 33$ indicates the convexity of the curves describing the dependence of the response on the corresponding factors and the presence of model extrema.

3. The absence of double and triple mixed sets of factors suggests that their effect on the quality indicator is insignificant.

Conversion of the coefficients from coded to natural ones yields the following regression equation:

$$
\begin{aligned}
& Y=0.393569+0.002994 \cdot \alpha+0.022585 \cdot \beta+0.011002 \cdot L-0.000044 \cdot \alpha \cdot \beta \\
& -0.000021 \cdot \alpha \cdot L-0.000021 \cdot \beta \cdot L-0.00006 \alpha^{2}-0.000667 \beta^{2}-0.000099 L^{2}
\end{aligned}
$$

This equation contains nine coefficients. The hypothesis about the adequacy of the mathematical model was tested using the Fisher's test. Based on the test results, the model was found to be adequate $F^{\text {calc }}=2.75<F^{\text {tab }}=3.2$.

Based on the data obtained, the response surfaces were constructed, that is the dependences of the uniformity of seed distribution of seeds along the furrow length.

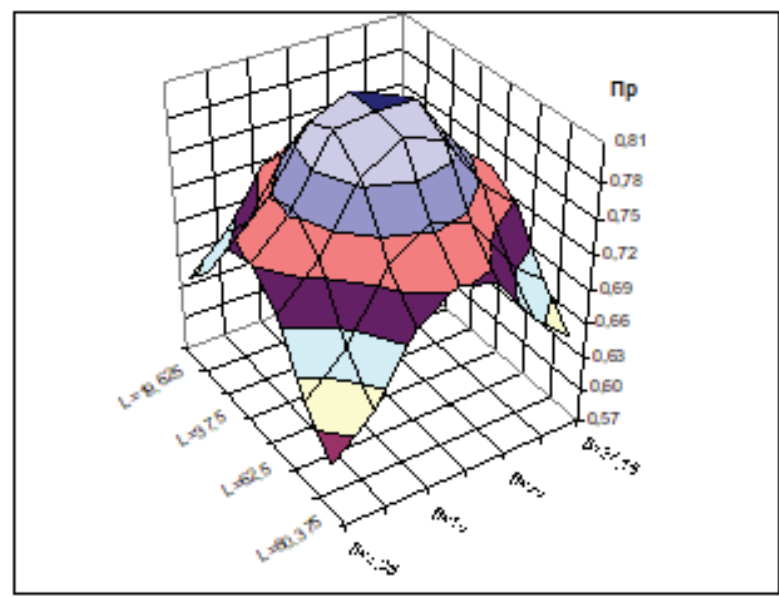

Figure 2: Dependencies $\pi p=f(\beta ; L)$, at $\alpha=5^{0}$.

\section{Conclusion}

In the study, the regression equation was obtained to construct the response surfaces. The analysis of the response surfaces shows that the optimal parameters for uniform seed distribution along the furrow length can be achieved at the approach angle $\alpha=250$, the roll angle $\beta=150$, and the cut length of the lower edge of the rack $L=50 \mathrm{~mm}$. 


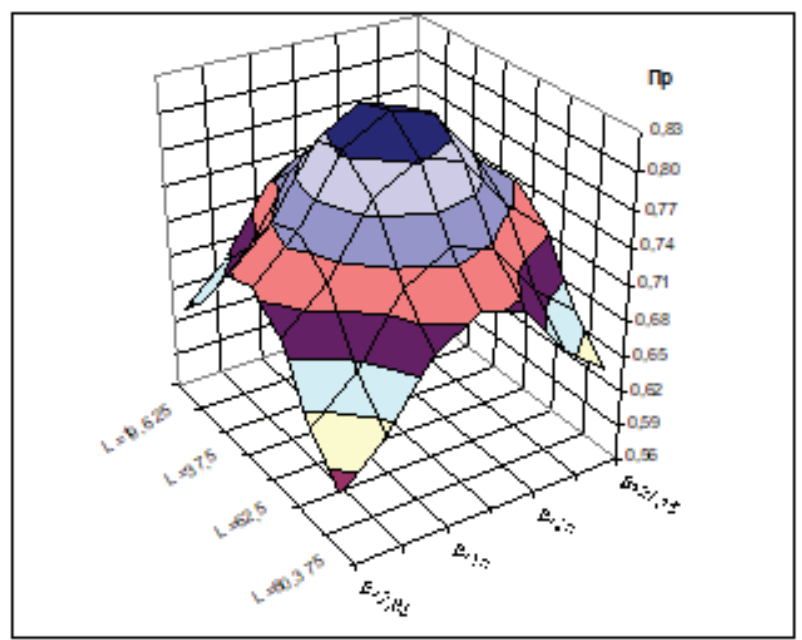

Figure 3: Dependencies $\pi p=f(\beta ; L)$, at $\alpha=15^{0}$.

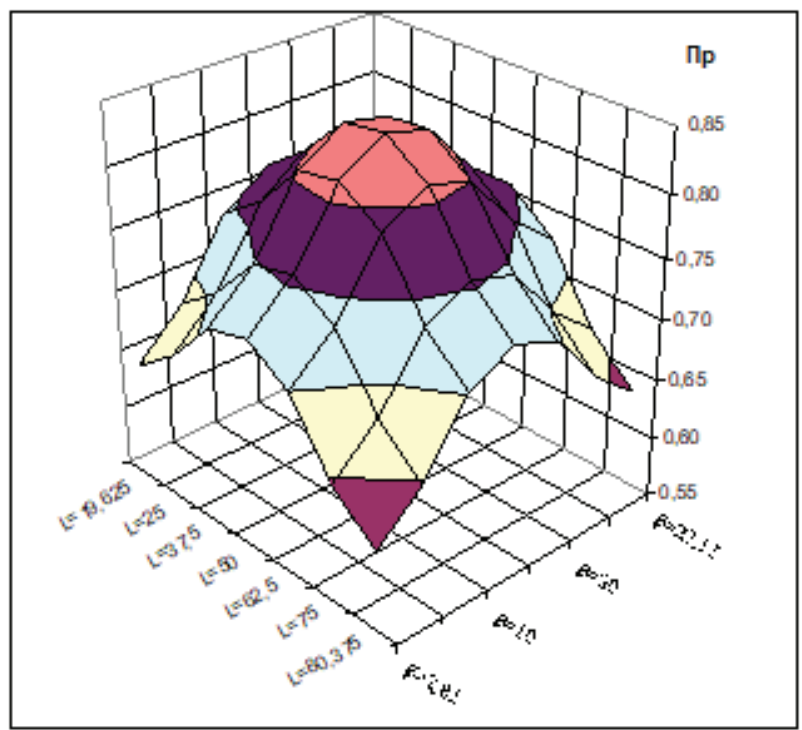

Figure 4: Dependencies $\pi p=f(\beta ; L)$, at $\alpha=25^{0}$.

\section{References}

[1] Russian Government (2012) State Program for the Development of Agriculture and Regulation of Markets for Agricultural Products, Raw Materials and Food for 20132020. Moscow: Minselkhoz.

[2] Lachuga, Y. F. (2009). Strategy of Machine and Technological Modernization of Agriculture in Russia for the Period up to 2020 Moscow: FGNU Rosinformagrotech.

[3] Russian Government. (2007). The Concept of the Development of Agricultural Science and Scientific Support of the Agro-Industrial Complex of the Russian Federation for the period up to 2025. Moscow: Minselkhoz. 
[4] Yushkevich, L. V. (2001). Resource-Saving System of Processing and Fertility of Chernozem Soils during the Intensification of the Cultivation of Grain Crops in the Southern Forest-Steppe of Western Siberia. (Dissertation, Candidate of Agriculture, Omsk, 2001).

[5] Bychkov, I. V., Lukovnikov, N. G. and Ruzhnikov, G. M. (2012). Implementation of Modern Information Technologies in the Tasks of Precision Farming. Presented at Information Technologies, Systems and Devices in the Agro-Industrial Complex: Proceedings of the 5th International Scientific-Practical Conference AGROINFO-70 Novosibirsk. June, Krasnoobsk, Russia. (vol. 1) Novosibirsk: Nauka, pp. 360-370.

[6] Checusov, M. S., et al. (2019). The Effect of Opener for Sowing and Fertilizing at Different Depths on the Quality and Yield of Spring Wheat Grain Advances in Social Science, Education and Humanities Research vol. 393 pp. 286-289.

[7] Demchuk, E. V., et al. (2018). Two-Cotton Sowing Soundry of Grain Crops with Different Mineral Fertilizer Level. Journal of Physics: Conference Series vol. 1059 issue 1 art. 012009

[8] Evchenko, A. V. (2006). Sowing Machines. Omsk: FGOU VPO Omsk State Agrarian University.

[9] Domrachev, V. A. (2011). Mechanization of Breeding Processes, Agriculture and Plant Growing. Omsk: Publishing House FGBOU VPO OmGAU.

[10] Zhidkov, G. A., Lavrukhin, P. V. and Ivanov, P. A. (2012). Evaluation of the Sowing Operation as an Element of Forecasting the Prospects of Crop Technology. Agricultural Machines and Technologies, vol. 1, pp. 19-21.

[11] Melnikov, S. V. (1980). Planning an Experiment in the Research of Agricultural Processes. Moscow: Nauka.

[12] Novik, F. S. (1980). Optimization of Metal Technology Processes by Methods of Planning Experiments. Moscow: Mechanical Engineering Sofia: Tekhnika.

[13] Ermakov, S. M. (1983). Mathematical Theory of Experiment Planning. Moscow: Nauka.

[14] Bolshev L. N. (1965). Tables of Mathematical Statistics. Moscow: Nauka.

[15] Patent' 72378, the Russian Federation, International Patent Classification A01C7/20 (2006.01); the Sowing coulter 2007144865; declared 03.12.2008; published 20.04.2008 Moscow. 